\title{
PGRMC1 localization and putative function in the nucleolus of bovine granulosa cells and oocytes
}

\author{
Laura Terzaghi ${ }^{1}$, Alberto Maria Luciano', Priscila C Dall'Acqua², Silvia C Modina, \\ John J Peluso ${ }^{3}$ and ValentinaLodde ${ }^{1}$ \\ ${ }^{1}$ Department of Health, Animal Science and Food Safety, Reproductive and Developmental Biology Laboratory, \\ University of Milan, Milan, Italy, ${ }^{2}$ School of Agricultural and Veterinarian Sciences, São Paulo State University \\ (UNESP), Jaboticabal, Brazil and ${ }^{3}$ Department of Obstetrics and Gynecology, University of Connecticut Health \\ Center, Farmington, Connecticut, USA
}

Correspondence should be addressed to V Lodde; Email: valentina.lodde@unimi.it

\begin{abstract}
Progesterone receptor membrane component-1 (PGRMC1) is a highly conserved multifunctional protein that is found in numerous systems, including reproductive system. Interestingly, PGRMC1 is expressed at several intracellular locations, including the nucleolus. The aim of this study is to investigate the functional relationship between PGRMC1 and nucleolus. Immunofluorescence experiments confirmed PGRMC1's nucleolar localization in cultured bovine granulosa cells (bGC) and oocytes. Additional experiments conducted on bGC revealed that PGRMC1 co-localizes with nucleolin (NCL), a major nucleolar protein. Furthermore, small interfering RNA (RNAi)-mediated gene silencing experiments showed that when PGRMC1 expression was depleted, NCL translocated from the nucleolus to the nucleoplasm. Similarly, oxidative stress induced by hydrogen peroxide $\left(\mathrm{H}_{2} \mathrm{O}_{2}\right)$ treatment, reduced PGRMC1 immunofluorescent signal in the nucleolus and increased NCL nucleoplasmic signal, when compared to non-treated cells. Although PGRMC1 influenced NCL localization, a direct interaction between these two proteins was not detected using in situ proximity ligation assay. This suggests the involvement of additional molecules in mediating the co-localization of PGRMC1 and nucleolin. Since nucleolin translocates into the nucleoplasm in response to various cellular stressors, PGRMC1's ability to regulate its localization within the nucleolus is likely an important component of mechanism by which cells response to stress. This concept is consistent with PGRMC1's well-described ability to promote ovarian cell survival and provides a rationale for future studies on PGRMC1, NCL and the molecular mechanism by which these two proteins protect against the adverse effect of cellular stressors, including oxidative stress. Reproduction (2018) 155 273-282
\end{abstract}

\section{Introduction}

Progesterone receptor membrane component-1 (PGRMC1) is a multifunctional protein that is highly conserved in eukaryotes. It belongs to the membraneassociated progesterone receptor (MAPR) family and is expressed in several mammalian organs and tissues (Runko et al. 1999, Raza et al. 2001, Sakamoto et al. 2004, Bali et al. 2013a,b), including those of the reproductive system (Zhang et al. 2008, Luciano et al. 2010, 2011, Aparicio etal. 2011, Keator etal. 2012, SaintDizier et al. 2012, Tahir et al. 2013, Kowalik et al. 2016). Specifically, PGRMC1 is expressed by granulosa and luteal cells of human, rodent, bovine and canine ovaries (Engmann et al. 2006, Peluso 2006, Aparicio et al. 2011, Luciano et al. 2011, Tahir et al. 2013, Griffin et al. 2014, Terzaghi et al. 2016), as well as oocytes (Luciano et al. 2010, 2013, Terzaghi et al. 2016).

Multiple functions are attributed to PGRMC1 (reviewed in Cahill 2007, Brinton et al. 2008, Neubauer et al. 2013, Peluso \& Pru 2014, Cahill et al. 2016, Ryu et al. 2017) as reflected by it being localized to numerous subcellular compartments. As predicted by the presence of a transmembrane domain, PGRMC1 localizes in several membranous compartments, such as the endoplasmic reticulum, the Golgi apparatus, the nuclear and plasma membranes, the endosomes and the secretory vesicles (Meyer et al. 1996, Raza et al. 2001, Bramley et al. 2002, Hand \& Craven 2003, Shin et al. 2003, Sakamoto et al. 2004, Min et al. 2005, Peluso et al. 2006, Zhang et al. 2008, Neubauer et al. 2009, Ahmed et al. 2010, Roy et al. 2010, Wu et al. 2011, Xu et al. 2011, Mir et al. 2012, 2013, Thomas et al. 2014). Interestingly, PGRMC1 is also detected in the nucleus (Beausoleil et al. 2004, Peluso et al. 2008, 2009, 2010a, 2012, Zhang et al. 2008, Ahmad et al. 2009, Luciano et al. 2010), specifically to the nucleolus (Ahmad et al. 2009, Luciano et al. 2010, Boisvert et al. 2012, Thul et al. 2017; http:// www.proteinatlas.org). This high compartmentalization suggests that at each site, PGRMC1 participates in the control of precise cellular processes. 
In order to shed light into the intricate story of PGRMC1's biological significance, it is important to dissect the function of PGRMC1 at each subcellular compartment. To this end, we have started to address whether PGRMC1 has a role in regulating the nucleolar function. Although the nucleolus' main function involves ribosome subunits production, recent advances describe it as a multifunctional subnuclear compartment. It appears that the nucleolus is a dynamic structure, which disassembles during mitosis and responds to signaling events during interphase. As such, it is involved in cell cycle control, especially regulating protein modifications such as sumoylation and phosphorylation or sequestrating specific proteins (Boisvert et al. 2007). Furthermore, it acts as a stress sensor mediating p53 stabilization in order to arrest cell cycle progression (Boisvert et al. 2007, Boulon et al. 2010).

Nucleolin ( $\mathrm{NCL}$ ) is the most abundant and wellcharacterized protein within the nucleolus, where it participates in ribosome biogenesis; however, NCL is also distributed in other subcellular compartments, such as the nucleoplasm, the cytoplasm and the cell surface (reviewed in Ginisty et al. 1999, Boisvert et al. 2007, Tajrishi et al. 2011, Jia et al. 2017). Numerous studies have shown that NCL subcellular localization is tightly correlated with its function under physiological and pathological conditions (Jia et al. 2017). Interestingly, experimental evidences have indicated that NCL has protective roles under cellular stress conditions such as heat stress, gamma irradiation and oxidative stress (Jia et al. 2017). Furthermore, translocation from the nucleolus to the nucleoplasm or cytoplasm seems to be part of the mechanism by which NCL participates in cellular stress response in different cell types (Daniely \& Borowiec 2000, Daniely et al. 2002, Zhang et al. 2010).
Thus, the overall goal of the present study is to examine the role of PGRMC1 on nucleolar function, particularly its relationship with NCL under normal and stress-induced conditions.

\section{Materials and methods}

\section{Reagents}

All the chemicals used in this study were purchased from SigmaAldrich except for those specifically mentioned. Gene silencing was performed by using the Stealth RNAi siRNA technology from Life Technologies as previously described (Terzaghi et al. 2016) using PGRMC1 Stealth RNAi (PGRMC1 RNAi: (RNA)GAG UUG UAG UCA AGU GUC UUG GUC U) within the coding region of the bovine PGRMC1 sequence (RefSeq: NM_001075133). Negative control (cat n. 12935-200) was chosen among the Stealth RNAi-negative control (CTRL RNAi) duplexes available from Life Technologies, designed to minimize sequence homology to any known vertebrate transcript. Primary antibodies used in this study are listed in Table 1.

\section{Sample collection}

Ovaries from Holstein dairy cows were recovered at the abattoir (INALCA S.p.A., Ospedaletto Lodigiano, LO, IT 2270 M CE, Italy) from pubertal females subjected to routine veterinary inspection and in accordance to the specific health requirements stated in Council Directive 89/556/ECC and subsequent modifications. Ovaries were transported to the laboratory within $2 \mathrm{~h}$ in sterile saline $(\mathrm{NaCl}, 9 \mathrm{~g} / \mathrm{L})$ maintained at $26^{\circ} \mathrm{C}$ and all subsequent procedures, unless differently specified, were performed at $35-38^{\circ} \mathrm{C}$. Bovine granulosa cells (bGC) were collected as previously described (Terzaghi et al. 2016). Briefly the content of $2-8 \mathrm{~mm}$ ovarian follicles, which typically contain fully grown oocytes, was aspirated and cumulus-oocyte complexes (COCs) were collected and

Table 1 List of antibodies used.

\begin{tabular}{|c|c|c|c|}
\hline Cell type & Technique & Primary antibody & Secondary antibody \\
\hline $\begin{array}{l}\text { Bovine granulosa } \\
\text { cells (bGC) }\end{array}$ & Immunofluorescence & $\begin{array}{l}\text { - Rabbit polyclonal anti-PGRMC1 (1:50; } \\
\text { Protein Tech, 12990-1-AP) } \\
\text { - Rabbit polyclonal anti-PGRMC1 (1:50; } \\
\text { Sigma, HPA002877) } \\
\text { - Mouse monoclonal anti-nucleolin (1:2000; } \\
\quad \text { Thermo Scientific, MA1-20800) }\end{array}$ & $\begin{array}{l}\text { - TRITC-labeled donkey anti-rabbit } \\
\text { (1:100; Vector Laboratories, Inc.) } \\
\text { - Alexa Fluor 488-labeled donkey } \\
\text { anti-mouse (1:1000; Life } \\
\text { Technologies) }\end{array}$ \\
\hline Oocytes & Immunofluorescence & $\begin{array}{l}\text { - Rabbit polyclonal anti-PGRMC1 (1:200; } \\
\text { Protein Tech, 12990-1-AP) } \\
\text { - Mouse monoclonal anti-nucleolin (1:2000; } \\
\quad \text { Thermo Scientific, MA1-20800) }\end{array}$ & $\begin{array}{l}\text { - TRITC-labeled donkey anti-rabbit } \\
\text { (1:100; Vector Laboratories, Inc.) } \\
\text { - Alexa Fluor 488-labeled donkey } \\
\text { anti-mouse (1:1000; Life } \\
\text { Technologies) }\end{array}$ \\
\hline $\begin{array}{l}\text { Bovine granulosa } \\
\text { cells (bGC) }\end{array}$ & In situ proximity ligation assay (PLA) & $\begin{array}{l}\text { - Rabbit polyclonal anti-PGRMC1 (Protein } \\
\text { Tech, 12990-1-AP-1:50) } \\
\text { - Mouse monoclonal anti-nucleolin (1:2000, } \\
\text { Thermo Scientific, MA1-20800) }\end{array}$ & $\begin{array}{l}\text { Anti-rabbit PLUS and anti-mouse } \\
\text { MINUS PLA probes (Duolink In } \\
\text { Situ PLA) }\end{array}$ \\
\hline $\begin{array}{l}\text { Bovine granulosa } \\
\text { cells (bGC) }\end{array}$ & Western blot & $\begin{array}{l}\text { - Rabbit polyclonal anti-PGRMC1 (1:200; } \\
\text { Protein Tech, 12990-1-AP) } \\
\text { - Rabbit polyclonal anti-PGRMC1 (1:50; } \\
\text { Sigma, HPA002877) } \\
\text { - Mouse monoclonal anti-beta tubulin } \\
\quad \text { (1:1000; Sigma, T8328) }\end{array}$ & $\begin{array}{l}\text { - Goat anti rabbit IgG peroxidase } \\
\text { conjugated (1:1000; Thermo } \\
\text { Scientific) } \\
\text { - Goat anti mouse IgG peroxidase } \\
\text { conjugated (1:1000; Thermo } \\
\text { Scientific) }\end{array}$ \\
\hline
\end{tabular}


processed for further immunofluorescence analysis (see below). Remaining follicular cells were washed in M199 supplemented with HEPES $20 \mathrm{mM}, 1790$ units/L heparin and $0.4 \%$ of bovine serum albumin (M199-D). The cell pellet was re-suspended in $1 \mathrm{~mL}$ of Dulbecco's modified growth medium supplemented with $10 \%$ of bovine calf serum, $100 \mathrm{U} / \mathrm{mL}$ penicillin $\mathrm{G}, 100 \mu \mathrm{g} /$ $\mathrm{mL}$, streptomycin and glutamax $100 \mathrm{U} / \mathrm{mL}$ (Gibco). The cell suspension was plated in a $25 \mathrm{~cm}^{2}$ flask with $6 \mathrm{~mL}$ of growth medium and incubated in humidified air at $37^{\circ} \mathrm{C}$ with $5 \% \mathrm{CO}_{2}$. After $24 \mathrm{~h}$, cells were gently washed with PBS and the growth medium was changed. Cells were incubated until confluence (typically 4-5 days), and then collected after trypsinization and re-plated according to the experimental design (see below).

Oocytes in their growing phase, characterized by a diffuse filamentous pattern of chromatin in the nuclear area and the presence of an active nucleolus were collected as previously described from 0.5 to $<2 \mathrm{~mm}$ early antral follicles by rupturing the follicle wall under the stereomicroscope (Lodde et al. 2008). Both COCs collected from 0.5 to $<2 \mathrm{~mm}$ and $2-8$ antral follicles were mechanically denuded using the vortex and fixed for further immunofluorescence analysis.

\section{RNAi treatment}

RNA interference (RNAi) experiments on bGC were conducted as previously described (Terzaghi et al. 2016). Cells were plated in a total number of $2 \times 10^{5}$ bGC cells in $2 \mathrm{~mL}$ of medium in 35-mm culture dishes and incubated in humidified air at $37^{\circ} \mathrm{C}$ with $5 \% \mathrm{CO}_{2}$. For immunofluorescent staining, cells were plated and cultured on cover glasses in 35-mm culture dishes under the same culture condition. After $24 \mathrm{~h}$, cells at $50-70 \%$ of confluence were transfected with $6 \mu \mathrm{L}$ of $20 \mu$ M PGRMC1 Stealth RNAi or CTRL RNAi combined with $10 \mu \mathrm{L}$ of Lipofectamine RNAi MAX (Life Technologies) in a final volume of $2 \mathrm{~mL}$ OPTIMEM (Life Technologies), according to the manufacturer protocol and cultured for $48 \mathrm{~h}$. After treatment cells were processed for further Western blotting and immunofluorescence analysis.

\section{Hydrogen peroxide $\left(\mathrm{H}_{2} \mathrm{O}_{2}\right)$ treatment}

Cells were plated on cover glasses and cultured as described for RNAi treatment to temporally match the two experiments. Thus, after $72 \mathrm{~h}$ of culture, cells were treated with $0.5 \mathrm{mmol} / \mathrm{L}$ hydrogen peroxide $\left(\mathrm{H}_{2} \mathrm{O}_{2}\right)$ for 90 min to induce acute $\mathrm{H}_{2} \mathrm{O}_{2}$ induced oxidative stress (Miguel et al. 2009). The same concentration was used for up to $24 \mathrm{~h}$ to study the role of $\mathrm{NCL}$ in mediating antiapoptotic action in cardiomyocytes and human umbilical vascular endothelial cells (HUVEC) (Jiang et al. 2010, Zhang et al. 2010). After treatment, cells were washed in PBS and fixed in 4\% paraformaldehyde for further immunofluorescence analysis. In addition, some cells were washed in culture medium and cultured for additional $24 \mathrm{~h}$ to assess the effect on nuclear morphology.

\section{Western blot analysis}

The levels of PGRMC1 protein expression in CTRL and PGRMC1 RNAi-treated bGC were assessed by Western blotting assay as previously described (Terzaghi et al. 2016). PGRMC1 or CTRL
RNAi-treated bGC were lysed in radioimmunoprecipitation assay (RIPA) buffer (50 mM Tris- $\mathrm{HCl}(\mathrm{pH} 7.4), 150 \mathrm{mM} \mathrm{NaCl}$, $1 \mathrm{mM}$ EDTA, 1\% Nonidet P-40 (NP-40), and 0.25\% sodium deoxycolate), supplemented with protease inhibitors and phosphatase inhibitors. All procedures were conducted on ice. Total amount of protein was determined using the Qubit Protein Assay Kit and Qubit fluorometer (Thermo Fisher Scientific). $20 \mu \mathrm{g}$ of total protein/lane were used for Western blottings. After the run, samples were transferred to nitrocellulose membrane (Bio-Rad), which were then incubated with $5 \%$ dry milk powder in TBS containing $0.1 \%$ tween (TBS/T) for $2 \mathrm{~h}$ at room temperature. PGRMC1 immunodetection was conducted using the rabbit polyclonal antibodies (Table 1) in 5\% dry milk TBS/T. PGRMC1 was revealed using a stabilized goat anti rabbit IgG peroxidase-conjugated antibody and detected using the Super Signal West Dura Extended Duration Substrate (Thermo Fisher Scientific). The nitrocellulose membrane was stripped in stripping buffer $(100 \mathrm{mM}$ 2-mercaptoethanol, $2 \%$ SDS and $62.5 \mathrm{mM}$ Tris- $\mathrm{HCl}(\mathrm{pH} 6.7)$ ) at $50^{\circ} \mathrm{C}$ for $30 \mathrm{~min}$ and re-probed with the anti-beta tubulin antibody at dilution 1:1000, which was revealed using a stabilized goat anti-mouse IgG peroxidase-conjugated antibody as loading control.

\section{Immunofluorescence}

Immunofluorescence staining was performed on bGC as previously described (Lodde \& Peluso 2011, Terzaghi et al. 2016). Briefly, cells grown and treated on cover glasses were fixed in $4 \%$ paraformaldehyde in PBS for $7 \mathrm{~min}$ and permeabilized with $0.1 \%$ triton-X in PBS for $7 \mathrm{~min}$. Samples were blocked with $20 \%$ normal donkey serum in PBS and incubated overnight at $4{ }^{\circ} \mathrm{C}$ with the rabbit anti-PGRMC1 antibody (Table 1). Double immunostaining was performed on bGC by incubating the samples with the rabbit anti-PGRMC1 or the mouse anti-NCL antibodies or a combination of the two. After incubation with secondary antibodies for $1 \mathrm{~h}$ at room temperature, samples were washed and finally mounted on slides in the antifade medium Vecta Shield (Vector Laboratories) supplemented with $1 \mu \mathrm{g} / \mathrm{mL}$ 40,6-diamidino-2-phenylindole (DAPI). Immunofluorescent analysis on bovine oocytes were performed as previously described (Luciano et al. 2010) on 4\% paraformaldehyde fixed oocytes. Immunofluorescent staining was performed as described for bGC with the exception that oocytes were fixed for $30 \mathrm{~min}$ at room temperature followed by $30 \mathrm{~min}$ and permeabilized with $0.3 \%$ Triton-X 100 for $10 \mathrm{~min}$.

bGC and oocytes were analyzed on an epifluorescence microscope (Eclipse E600; Nikon) equipped with a $40 \times$ and a $60 \times$ objective, a digital camera (Nikon digital sight, DS-U3) and software (NIS elements Imaging Software; Nikon). Immunofluorescence negative controls, which were performed by omitting one or both the primary antibodies, did not show any staining under the same exposure settings. Images that were used for image quantification analysis were captured under the same settings.

\section{In situ proximity ligation assay (PLA)}

In situ proximity ligation assay (PLA; Duolink SIGMA) was used to assess the interaction between PGRMC1 and 
nucleolin in bGC following the manufacturer protocol. Primary antibodies for PGRMC1 and nucleolin were the same used for immunofluorescence, while anti-rabbit PLUS and anti-mouse MINUS PLA probes were used as secondary antibodies. Negative controls were performed omitting one of the two primary antibodies. Cells were mounted with Duolinkmounting medium.

\section{Image analysis}

Quantification of fluorescent intensity (FI) signal was performed using the ImageJ software (https://imagej.net). The nucleolar signal of PGRMC1 in bGC was quantified calculating the integrated density of PGRMC1 signal selecting the whole PGRMC1-positive areas in the nucleus of a total of 50 cells for each treatment (CTRL RNAi and PGRMC1 RNAi treated cells from 3 independent replicates) at $48 \mathrm{~h}$ after RNAi treatment. Data were polled and the mean FI of the CTRL RNAi-treated group was set at $100 \%$. FI values of the CTRL RNAi and PGRMC1 RNAi treatments were expressed as a percentage of the mean CTRL RNAi value. For image quantification of the NCL nucleolar and nucleoplasmic signals, threshold was selected by choosing a cutoff value such that all the nucleolar areas with an intense NCL signal within each cell. Then, the NCL total nuclear FI was assessed by selecting the whole nuclear area and calculating the integrated density of the corresponding regions of interests (ROI) of a total of 50 randomly selected nuclei in CTRL RNAi and PGRMC1 RNAitreated cells. The NCL nucleolar signal was calculated by analyzing the integrated density of the threshold area in each nucleus, while the NCL nucleoplasmic signal was calculated by subtracting the total nucleolar $\mathrm{FI}$ to the total nuclear $\mathrm{FI}$ of each nucleus. Data were polled and the mean nucleoplasmic $\mathrm{NCL} \mathrm{FI}$ of the CTRL RNAi-treated group was set at $100 \%$. FI values of the CTRL RNAi and PGRMC1 RNAi treatments were expressed as a percentage of the mean CTRL RNAi value. Background signals did not change significantly among treatments. To assess the effect of $\mathrm{H}_{2} \mathrm{O}_{2}$-induced oxidative stress on PGRMC1 and NCL localization, the same analysis was performed on a total of 75 cells from 3 independent replicates for each treatment (non-treated and $\mathrm{H}_{2} \mathrm{O}_{2}$-treated cells) after 90 min of $\mathrm{H}_{2} \mathrm{O}_{2}$ treatment.

\section{Statistical analysis}

Experiments were run in triplicates. All statistical analysis was done using Prism software (GraphPad Prism v. 6.0e). Data from the replicate experiments were pooled and the data expressed as a mean \pm S.E.M. Student's $t$-test was used to determine the differences between two groups.

\section{Results}

\section{PGRMC1 localization}

Immunofluorescence analysis indicated that PGRMC1 localized to areas of the interphase nucleus that were not stained by DAPI. PGRMC1's nuclear localization in bGC was the same regardless of which PGRMC1 antibody was used (Fig. 1). However, nuclear staining for PGRMC1 with the Sigma Prestige antibody displayed a diffuse signal with the staining associated with DAPInegative areas and only slightly more intense than that observed for the overall nucleus. In contrast, the non-DAPI stained areas within the nucleus were more intensely stained using the PGRMC1 antibody provided by Proteintech (Fig. 1). These non-DAPI-stained areas typically correspond to areas of the interphase nucleus where the nucleoli reside.

\section{PGRMC1 co-localization with NCL}

To further characterize PGRMC1 localization in the nucleus, we evaluated its co-localization with the nucleolar marker, NCL, in both cultured bGC and bovine growing and fully grown oocytes. Immunofluorescence data indicated that the two proteins co-localized in the nucleolus of bGC as shown in Fig. 2; PGRMC1 signal appeared as a dotted pattern in the area corresponding to the nucleolus compared to NCL signal, which fully covered the nucleolus (i.e. nuclear areas not stained by DAPI). Although co-localized, in situ proximity ligation assay did not detect an interaction between PGRMC1 and NCL, indicating the absence of a direct interaction between the two proteins in bGC.
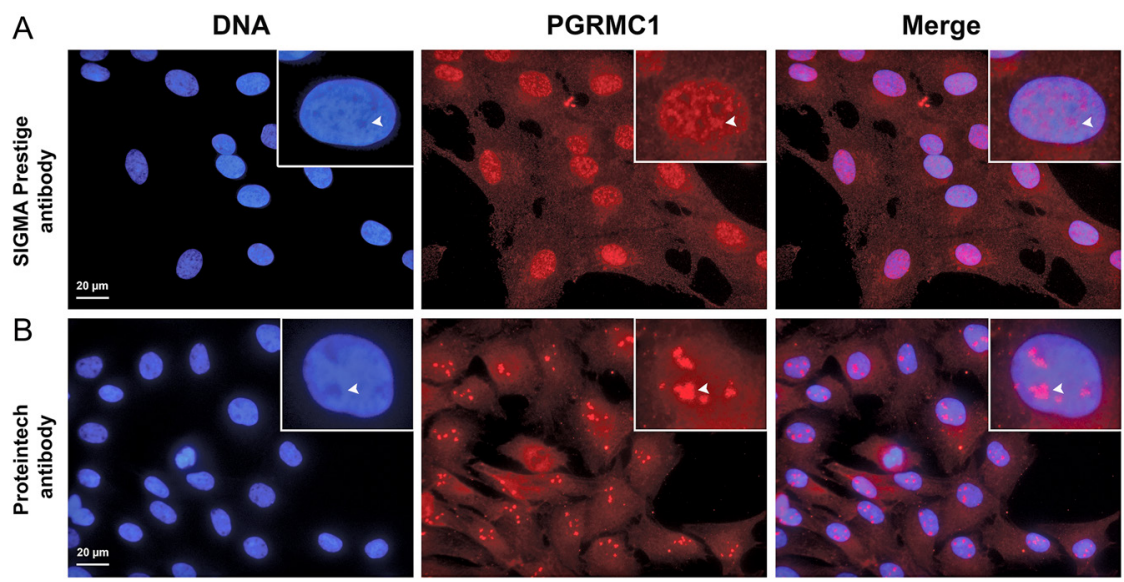

Figure 1 PGRMC1 immunofluorescent localization (red) in bGC obtained using SIGMA Prestige (A) and the Protein Tech (B) rabbit polyclonal antibodies. DNA is stained with DAPI (blue). Insets show a single magnified nucleus. Note that both antibodies show intense staining in DAPI-negative areas (arrows). 

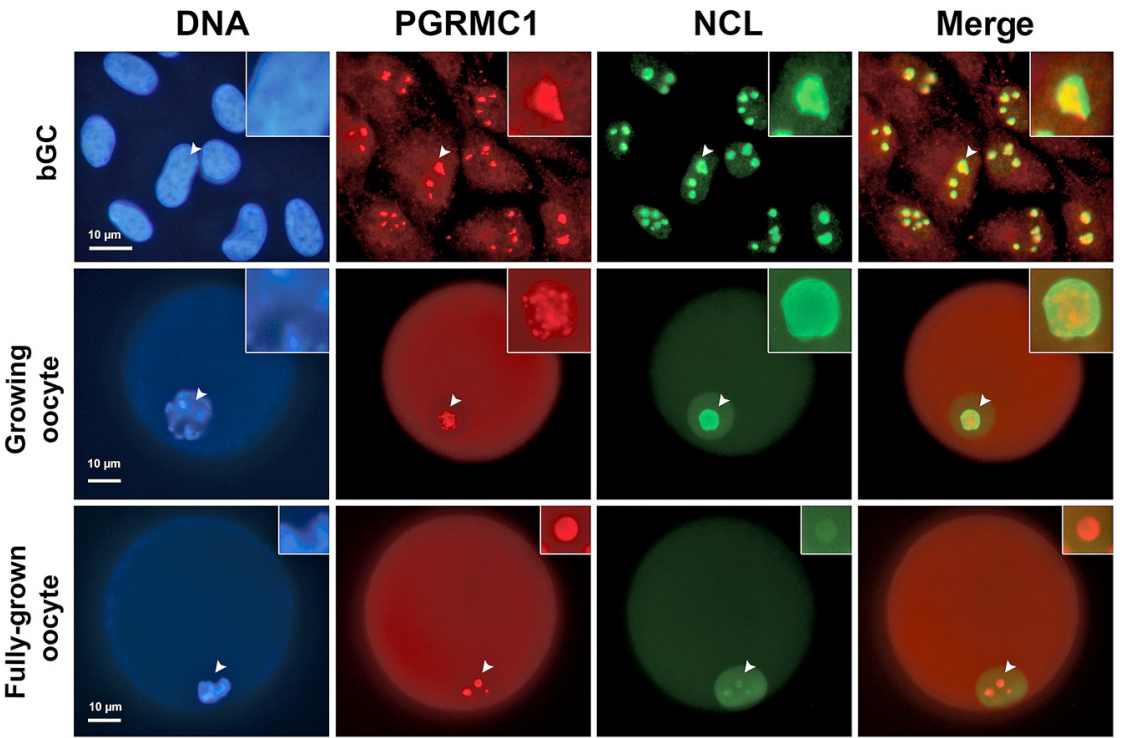

Figure 2 PGRMC1 (red) and NCL (green) immunofluorescence localization in bGC, growing oocytes and fully grown oocytes. DNA is stained with DAPI (blue). Merged images show partial PGRMC1-nucleolin co-localization (yellow). Insets represent $3 \times$ magnification.
In growing bovine oocytes, which are characterized by the presence of an active nucleolus (Fair et al. 1996, Lodde et al. 2008), NCL marked the nucleolus and showed a light diffuse staining pattern in the nucleoplasm as previously described (Fair et al. 2001, Baran et al. 2004, Maddox-Hyttel et al. 2005). In particular, $\mathrm{NCL}$ nucleolar signal was intense and slightly more concentrated at the periphery of the nucleolus. In these oocytes PGRMC1 localized in the nucleolus showing a dotted staining pattern, similar to that observed in bGC nucleoli (Fig. 2). In fully grown oocytes (Fig. 2), which typically displayed inactive nucleolar remnants (Fair et al. 1996, Lodde et al. 2008), NCL was mainly dispersed in the nucleoplasm with a faint staining in the nucleolar remnants as previously described (Fair et al. 2001, Baran et al. 2004, Maddox-Hyttel et al. 2005). In these oocytes, PGRMC1 concentrated in one or multiple dots where it co-localized with NCL.

\section{Assessment of PGRMC1 and nucleolin functional interaction}

In order to establish the possible functional relationship between PGRMC1 and NCL, we silenced PGRMC1 expression in bGC by using RNAi. The RNAi protocol was previously validated by quantitative reverse transcriptase-polymerase chain reaction (qRT-PCR) showing a significant reduction of PGRMC1 mRNA levels compared to CTRL RNAi-treated group (Terzaghi et al. 2016). That PGRMC1 expression was reduced after $48 \mathrm{~h}$ PGRMC1-RNAi treatment was confirmed by Western blot analysis, regardless of which PGRMC1 antibody was used. As shown in Fig. 3A, PGRMC1 was present in multiple bands, whose intensity decreased after $48 \mathrm{~h}$ of PGRMC1 RNAi treatment. Moreover, quantification of PGRMC1 nucleolar immunofluorescent signal in PGRMC1 and CTRL RNAi-treated bGC revealed an approximate $40 \%$ decrease in PGRMC1 abundance in the nucleolus, which also gives confirmation of the specificity of PGRMC1's nucleolar localization (Fig. 3B and C).

In order to assess the functional relationship between PGRMC1 and NCL, the effect of depleting PGRMC1 on the localization of NCL was evaluated. As shown in Fig. 4, when PGRMC1 was depleted, a significantly higher quantity of NCL was present in the nucleoplasm when compared to the CTRL RNAi-treated group. The same relationship was observed when cultured bGC were subjected to $90 \mathrm{~min}$ of $\mathrm{H}_{2} \mathrm{O}_{2}$-induced oxidative stress. As shown in Fig. 5A, nuclear morphology was similar to controls after a $90 \mathrm{~min}$ exposure to $\mathrm{H}_{2} \mathrm{O}_{2}$, when compared to the CTRL group. Importantly, when bGC were washed to remove $\mathrm{H}_{2} \mathrm{O}_{2}$ and cultured for additional $24 \mathrm{~h}$, virtually all the bGC appears to be apoptotic as judged by nuclear morphology after DNA staining, while non-treated cells did not show any sign of nuclear damage. Moreover, when compared to nontreated cells, PGRMC1 nucleolar signal decreased (Fig. 5B) while NCL nucleoplasmic signal increased in $\mathrm{H}_{2} \mathrm{O}_{2}$-treated cells (Fig. 5C).

\section{Discussion}

The present findings demonstrate that PGRMC1 localizes to the nucleolus of both bovine granulosa cells and oocytes, suggesting that PGRMC1 has a role in regulating the function of the nucleolus of these two cell types. The prominent nucleolar localization of PGRMC1 as revealed using the Protein Tech antibody is consistent with investigations of non-ovarian cells that detect PGRMC1 within the nucleolus by either immunohistochemistry or mass spectrometric analysis (Ahmad et al. 2009, Luciano et al. 2010, Boisvert et al. 2012, Thul et al. 2017) (see also http://www.proteinatlas. 
A
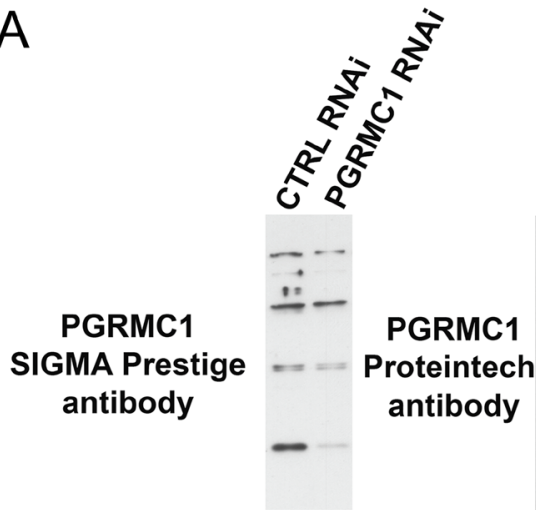

beta TUB

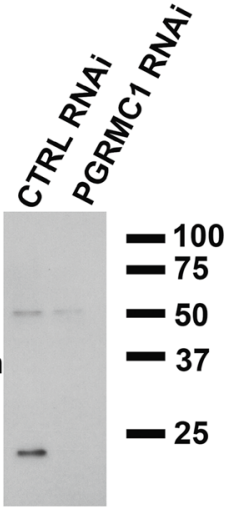

beta TUB

$-50$

\section{B PGRMC1 Staining}

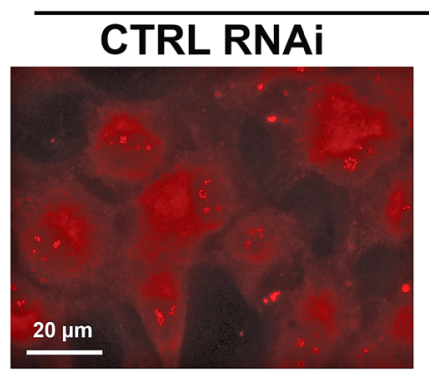
PGRMC1 RNAi

C PGRMC1 nucleolar signal

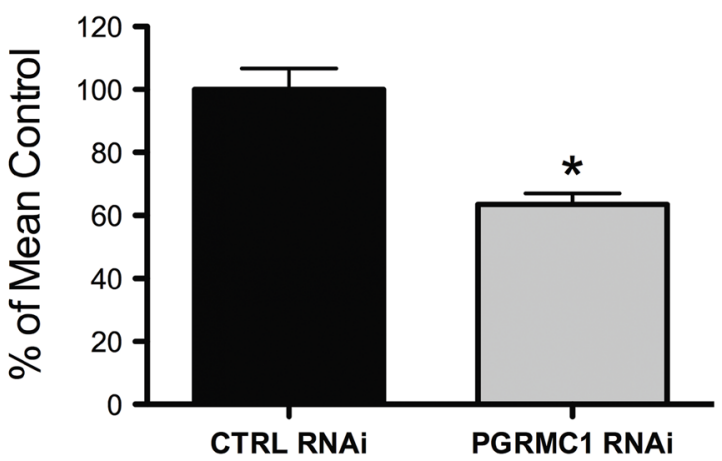

Figure 3 Effect of PGRMC1 RNAi mediated gene silencing on PGRMC1 expression. (A) Representative Western blotting analysis showing PGRMC1 protein levels in PGRMC1 and CTRL RNAi-treated bGC after $48 \mathrm{~h}$ of treatment using the SIGMA Prestige and the Proteintech rabbit polyclonal antibodies. Beta tubulin was used as loading control. (B) Representative images showing PGRMC1 immunofluorescent staining in PGRMC1 and CTRL RNAi-treated bGC. (C) Graph showing analysis of PGRMC1 immunofluorescence intensity in the nucleolus of PGRMC1 and CTRL RNAi-treated bGC after $48 \mathrm{~h}$ of treatment; ${ }^{*}$ indicates significant difference $(t$-test, $P<0.05, n=50$ ).
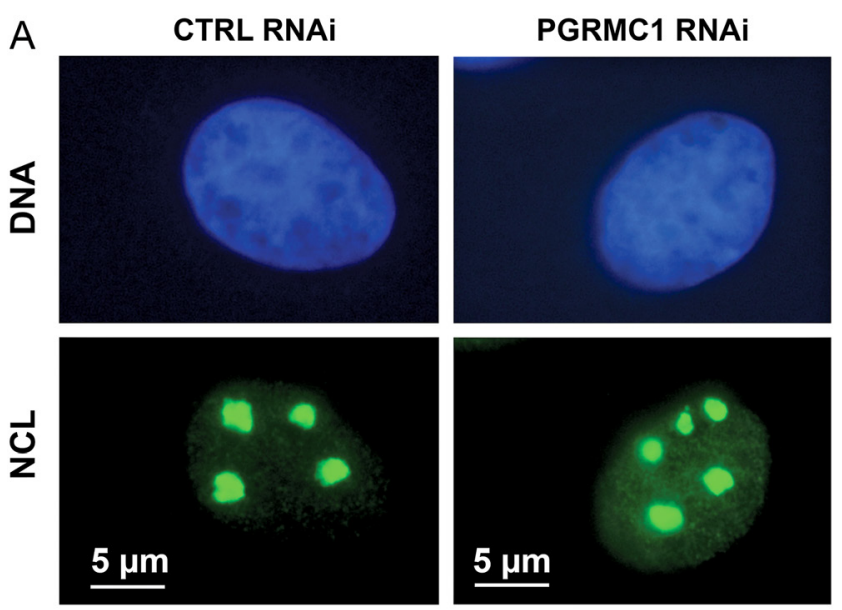

B

NCL nucleoplasmic Signal

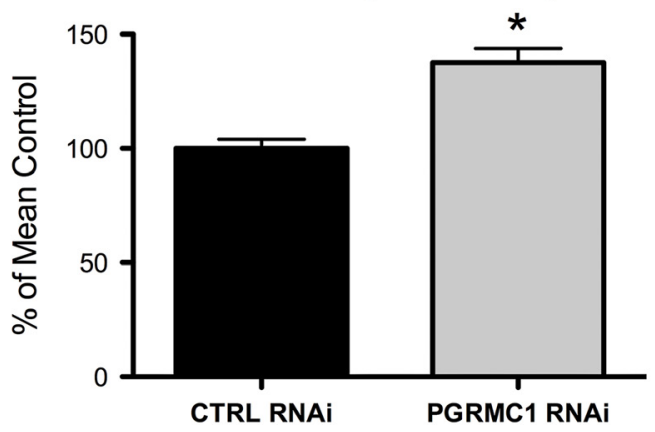

Figure 4 Effect of PGRMC1 RNAi-mediated gene silencing on $\mathrm{NCL}$ localization. (A) Representative images showing NCL immunofluorescent staining in PGRMC1 and CTRL RNAi treated bGC; note the increased nucleoplasmic signal in PGRMC1 RNAi treated cell. (B) Graph showing analysis of PGRMC1 immunofluorescence intensity in the nucleoplasm of PGRMC1 and CTRL RNAi treated bGC after $48 \mathrm{~h}$ of treatment; *indicates significant difference ( $t$-test, $P<0.05, n=50$ ).

org). However, the rabbit polyclonal antibody to PGRMC1 provided by Sigma Prestige detects PGRMC1 not only within the nucleolus but also in other interchromatin regions that resemble the nuclear speckles (Spector \& Lamond 2011). The reason for this discord likely relates to the two antibodies detecting different molecular weight forms of PGRMC1. Western blots using either the Proteintech or the Sigma Prestige antibody detect PGRMC1 as bands at $\approx 25$ and $\approx 55 \mathrm{kDa}$, while the Sigma antibody also detects an additional band at $37 \mathrm{kDa}$ and two bands greater than $55 \mathrm{kDa}$. All the bands detected by either antibody are specific since their intensity is decreased in PGRMC1 RNAi-treated cells. The different size forms of PGRMC1 are due to dimerization and posttranslational modifications such as phosphorylation and sumoylation (Neubauer et al. 2008, Peluso et al. 2010b, 2012, Kabe et al. 2016). Therefore, it is not surprising that polyclonal antibodies obtained using different 
A
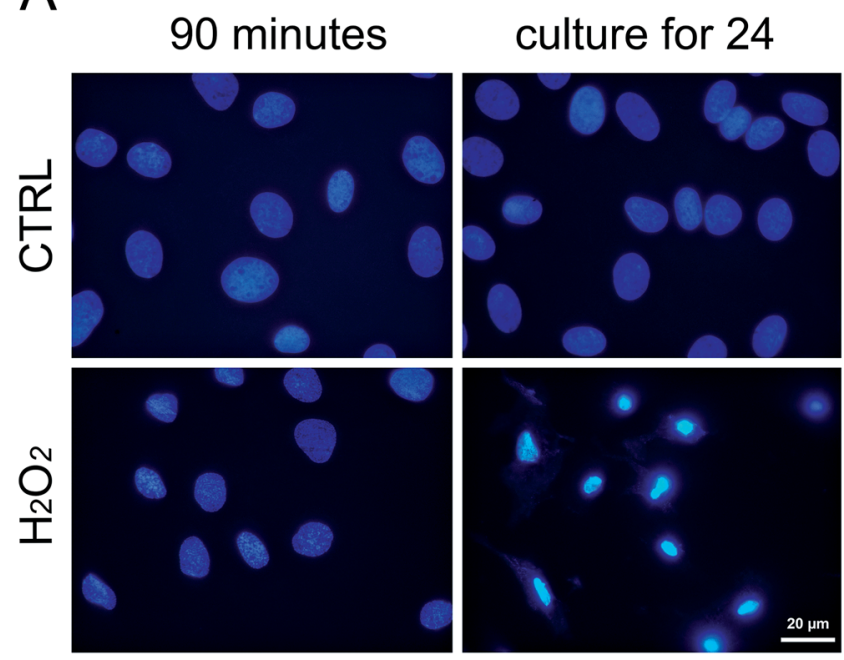

B

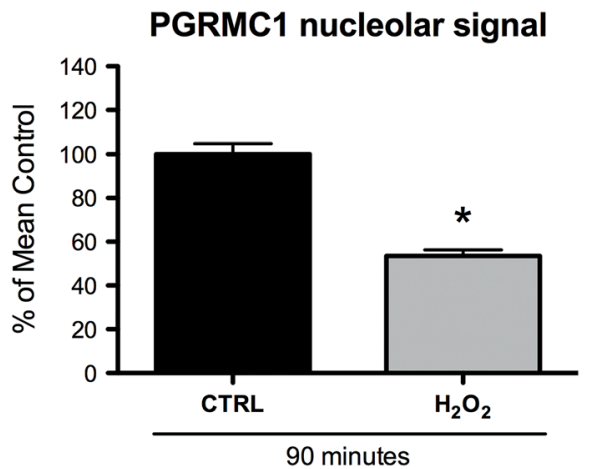

C

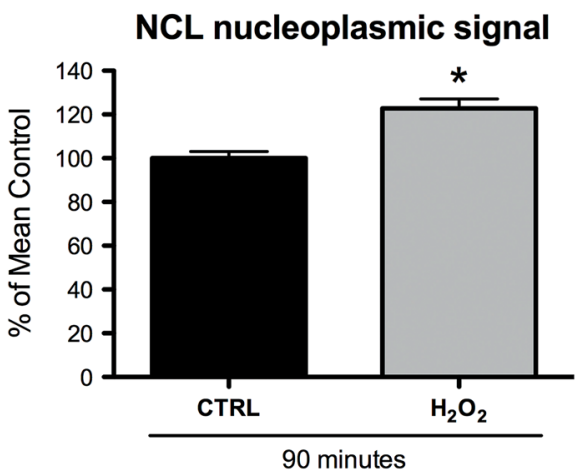

Figure 5 Effect of $\mathrm{H}_{2} \mathrm{O}_{2}$ treatment on nuclear morphology, and PGRMC1 and NCL localization. (A) Pictures in the left panel show the nuclear morphology (as assessed by DAPI staining) in CTRL group (not treated) and $\mathrm{H}_{2} \mathrm{O}_{2}$-treated bGC for $90 \mathrm{~min}$. Pictures in the right panel show effect on nuclear morphology after washing and culturing the cells for additional $24 \mathrm{~h}$ in both CTRL and $\mathrm{H}_{2} \mathrm{O}_{2}$-treated groups. ( $\mathrm{B}$ and C) Graphs show analysis of PGRMC1 and NCL immunofluorescence intensity in the nucleolus and nucleoplasm, respectively, in nontreated bGC (CTRL) and $\mathrm{H}_{2} \mathrm{O}_{2}$ treatment after 90 min of culture; *indicates significant difference ( $t$-test, $P<0.05, n=75$ ).

immunogens may preferentially recognize one or multiple forms of PGRMC1, which in turn might preferentially localize in different subcellular compartment.
Because the Proteintech antibody precisely localizes PGRMC1 to the nucleolus, it was used to determine whether PGRMC1 co-localizes with the nucleolar protein, NCL. This approach reveals that PGRMC1 and $\mathrm{NCL}$ co-localizes to the nucleolus in bGC. Moreover, depletion of PGRMC1 results in NCL within the nucleolus redistributing to nucleoplasm in these cells. Thus, localization of NCL is likely dependent in part on PGRMC1. This observation is important since $\mathrm{NCL}$ mobilization from the nucleolus into the nucleoplasm is induced by different types of cellular stress. For example, heat shock, ionizing radiation and hypoxia all promote the translocation of NCL into the nucleoplasm (Daniely \& Borowiec 2000, Daniely et al. 2002). In particular, $\mathrm{NCL}$ redistribution is induced by heat stress in HeLa cells and accompanied by an increase in the formation of a complex between NCL and replication protein A (RPA) (Daniely \& Borowiec 2000), which exerts important functions during DNA replication (Iftode et al. 1999). NCL-RPA interaction in turn strongly inhibits DNA replication, likely by sequestering RPA away from sites of ongoing DNA synthesis (Daniely \& Borowiec 2000). Other studies in U2-OS and U2-OS p53-depleted cells demonstrate that $\mathrm{NCL}$ redistribution occurs when stress is induced by $\gamma$-irradiation and treatment with the radiomimetic agent, camptothecin. Under these stress conditions, NCL binds p53, which facilitates its transit into the nucleoplasm (Daniely et al. 2002).

The stress-induced changes in NCL's localization suggest that various stressors alter PGRMC1's ability to retain $\mathrm{NCL}$, which would allow $\mathrm{NCL}$ to transit to the nucleoplasm. Our study demonstrates that $\mathrm{H}_{2} \mathrm{O}_{2}$ induced oxidative stress decreases the PGRMC1 signal in the nucleolus and increases the nucleoplasmic $\mathrm{NCL}$ signal, further reinforcing this concept. The $\mathrm{H}_{2} \mathrm{O}_{2}-$ induced oxidative stress model is biologically relevant in the ovary, especially during luteolysis. Reactive oxygen species (ROS) are indeed released locally by leucocytes invading the corpus luteum, which induce apoptosis of ovarian luteal cells (Vega et al. 1995, Davis \& Rueda 2002, Del Canto et al. 2007, Will et al. 2017). Moreover, it has been recently shown that PGRMC1 participates in this process since inhibition of PGRMC1 using an antagonist (AG205) eliminates P4's ability to prevent $\mathrm{H}_{2} \mathrm{O}_{2}$-induced apoptosis in human granulosa/luteal cells (Will et al. 2017). Interestingly, it has been proposed that AG205 may act by promoting PGRMC1's translocation from the nucleus to the cytoplasm and by regulating the expression of Harakiri $(\mathrm{Hkr})$, which is a $\mathrm{BH}-3$ only member of the B-cell lymphoma 2 (BCL2) family that promotes apoptosis by binding to and antagonizing the antiapoptotic action of BCL2- and BCL2-like proteins (Will et al. 2017). These observations are consistent with the NCL's role in regulating $\mathrm{H}_{2} \mathrm{O}_{2}$-induced apoptosis in HUVEC (Zhang et al. 2010) and cardiomyocytes (Jiang et al. 2010). 
The precise mechanism by which PGRMC1 controls $\mathrm{NCL}$ localization and function remains to be further explored. To start to assess this issue, we have focused on the nature of PGRMC1/NCL association in the nucleolus. Although PGRMC1 and NCL often co-localize to the same sub-region of the nucleolus of bGC, they do not seem to directly interact, since we were not able to demonstrate a direct interaction using the PLA assay. This might suggest that their functional interaction could involve the participation of other yet to be identified protein. Interestingly, a known PGRMC1-binding protein, Plasminogen Activator Inhibitor 1 RNA-Binding Protein (PAIRBP1) (Peluso et al. 2006, 2008, 2013) (also known as SERPINE1 mRNA-Binding Protein 1), which is typically found in the cytoplasm, localizes to the nucleolus under specific experimental stress-induced conditions in HeLa cells (Lee et al. 2014). Therefore, it is possible that under stress conditions PAIRBP1 translocates to the nucleolus and competes with this putative intermediary protein for binding to PGRMC1. This would potentially interfere with PGRMC1' ability to retain NCL within the nucleolus and account for the translocation of nucleolin from the nucleolus into the nucleoplasm under stress condition.

Finally, the present study reveals the relationship between PGRMC1 and NCL in bovine oocytes. PGRMC1 is present in the nucleolus of growing oocytes and the signal is retained to some extent in the nucleolar remnants of fully grown bovine oocytes. During growth, the oocyte's nucleus is characterized by the presence of a diffuse filamentous transcriptionally active chromatin and by a functional fibrillogranular nucleolus, which is gradually disassembled forming the so called 'nucleolar remnants', along with the progressive inactivation of rRNA synthesis that occurs at the end of oocyte growth (Fair et al. 1996, Lodde et al. 2008). Ultrastructurally, the nucleolar remnants appear as electron dense spheres often showing a semilunar fibrillar center-like structures attached (Fair et al. 1996, Lodde et al. 2008). In bovine oocytes, proteins such as RNA polymerase I and Upstream Binding Factor (UBF) remain associated to the inactive nucleolar remnants, while others, such as $\mathrm{NCL}$ and nucleophosmin mostly disperse in the nucleoplasm (Fair et al. 2001, Baran et al. 2004, Maddox-Hyttel et al. 2005). Upon meiotic resumption and during oocyte maturation the nucleolar remnant further disassembles and nucleolar proteins are probably dispersed in the cytoplasm. After fertilization the so-called 'nucleolar precursor bodies' (NPBs) appear as electron dense compact spheres in the male and female pronuclei reviewed in Maddox-Hyttel et al. (2005). The NPBs serve for the re-establishment of a functional fibrillogranular nucleolus, which in bovine occurs at the time of major embryonic genome activation (at the 8- to 16-cell stage). It has been proposed that proteins engaged in late rRNA processing of maternal origin, including $\mathrm{NCL}$, are to some extent re-used for nucleologenesis in the embryo while others need to be de novo transcribed before being incorporated in the nucleolus (reviewed in Maddox-Hyttel et al. 2005). In this scenario, PGRMC1 localization in growing and fully-grown oocytes and in the NPBs of bovine zygotes (Luciano et al. 2010) suggests a role in both the disassembly and the reassembly of the nucleolus during meiosis and early embryogenesis. Interestingly, in growing oocytes, as well as in bGC, PGRMC1 and NCL show a different localization pattern, with PGRMC1 present in a dotted pattern. A similar pattern in growing bovine oocytes has been reported for the RNA polymerase I-specific transcription initiation factor, UBF (Baran et al. 2004). In future studies, it will be important to assess whether a specific functional interaction between $\mathrm{NCL}$ or other nucleolar proteins and PGRMC1 exists during early embryonic development and thereby influences the embryogenesis.

\section{Declaration of interest}

The authors declare that there is no conflict of interest that could be perceived as prejudicing the impartiality of the research reported.

\section{Funding}

This work was supported by CIG - Marie Curie Actions FP7Reintegration-Grants within the 7th European Community Framework Programme (Contract: 303640, 'Pro-Ovum') awarded to $\mathrm{V}$ L, 'Fondo Piano di sviluppo UNIMI linea B Giovani ricercatori' - Grant n.: 15-6-3027000-54, awarded to V L and Fondo Linea 2B - 2016 - Grant n.: 15-6-3027000-81, awarded to A M L; P C D A is supported by Scholarship from Capes foundation /PDSE/88881.134900/2016-01.

\section{References}

Ahmad Y, Boisvert FM, Gregor P, Cobley A \& Lamond Al 2009 NOPdb: nucleolar proteome database - 2008 update. Nucleic Acids Research 37 D181-D184. (https://doi.org/10.1093/nar/gkn804)

Ahmed IS, Rohe HJ, Twist KE \& Craven RJ 2010 Pgrmc1 (progesterone receptor membrane component 1) associates with epidermal growth factor receptor and regulates erlotinib sensitivity. Journal of Biological Chemistry 285 24775-24782. (https://doi.org/10.1074/jbc. M110.134585)

Aparicio IM, Garcia-Herreros M, O'Shea LC, Hensey C, Lonergan P \& Fair T 2011 Expression, regulation, and function of progesterone receptors in bovine cumulus oocyte complexes during in vitro maturation. Biology of Reproduction 84 910-921. (https://doi. org/10.1095/biolreprod.110.087411)

Bali N, Arimoto JM, Morgan TE \& Finch CE 2013a Progesterone antagonism of neurite outgrowth depends on microglial activation via Pgrmc1/S2R. Endocrinology 154 2468-2480. (https://doi.org/10.1210/en.2012-2109)

Bali N, Morgan TE \& Finch CE 2013b Pgrmc1: new roles in the microglial mediation of progesterone-antagonism of estradiol-dependent neurite sprouting and in microglial activation. Frontiers in Neuroscience 7157. (https://doi.org/10.3389/fnins.2013.00157)

Baran V, Pavlok A, Bjerregaard B, Wrenzycki C, Hermann D, Philimonenko VV, Lapathitis G, Hozak P, Niemann H \& Motlik J 2004 Immunolocalization of upstream binding factor and pocket protein $\mathrm{p} 130$ during final stages of bovine oocyte growth. Biology of Reproduction 70 877-886. (https://doi.org/10.1095/biolreprod.103.018408) 
Beausoleil SA, Jedrychowski M, Schwartz D, Elias JE, Villen J, Li J, Cohn MA, Cantley LC \& Gygi SP 2004 Large-scale characterization of HeLa cell nuclear phosphoproteins. PNAS 101 12130-12135. (https:// doi.org/10.1073/pnas.0404720101)

Boisvert FM, van Koningsbruggen S, Navascues J \& Lamond Al 2007 The multifunctional nucleolus. Nature Reviews Molecular Cell Biology 8 574-585. (https://doi.org/10.1038/nrm2184)

Boisvert FM, Ahmad Y, Gierlinski M, Charriere F, Lamont D, Scott M, Barton G \& Lamond Al 2012 A quantitative spatial proteomics analysis of proteome turnover in human cells. Molecular and Cellular Proteomics 11 M111.011429. (https://doi.org/10.1074/mcp.M111.011429)

Boulon S, Westman BJ, Hutten S, Boisvert FM \& Lamond AI 2010 The nucleolus under stress. Molecular Cell 40 216-227. (https://doi. org/10.1016/j.molcel.2010.09.024)

Bramley TA, Menzies GS, Rae MT \& Scobie G 2002 Non-genomic steroid receptors in the bovine ovary. Domestic Animal Endocrinology 23 3-12. (https://doi.org/10.1016/S0739-7240(02)00140-6)

Brinton RD, Thompson RF, Foy MR, Baudry M, Wang J, Finch CE, Morgan TE, Pike CJ, Mack WJ, Stanczyk FZ et al. 2008 Progesterone receptors: form and function in brain. Frontiers in Neuroendocrinology 29 313-339. (https://doi.org/10.1016/j.yfrne.2008.02.001)

Cahill MA 2007 Progesterone receptor membrane component 1: an integrative review. Journal of Steroid Biochemistry and Molecular Biology 105 16-36. (https://doi.org/10.1016/j.jsbmb.2007.02.002)

Cahill MA, Jazayeri JA, Catalano SM, Toyokuni S, Kovacevic Z \& Richardson DR 2016 The emerging role of progesterone receptor membrane component 1 (PGRMC1) in cancer biology. Biochimica et Biophysica Acta 1866 339-349. (https://doi.org/10.1016/j. bbcan.2016.07.004)

Daniely Y \& Borowiec JA 2000 Formation of a complex between nucleolin and replication protein A after cell stress prevents initiation of DNA replication. Journal of Cell Biology 149 799-810. (https://doi. org/10.1083/jcb.149.4.799)

Daniely Y, Dimitrova DD \& Borowiec JA 2002 Stress-dependent nucleolin mobilization mediated by p53-nucleolin complex formation. Molecular and Cellular Biology 22 6014-6022. (https://doi.org/10.1128/ MCB.22.16.6014-6022.2002)

Davis JS \& Rueda BR 2002 The corpus luteum: an ovarian structure with maternal instincts and suicidal tendencies. Frontiers in Bioscience 7 d1949-d1978. (https://doi.org/10.2741/davis1)

Del Canto F, Sierralta W, Kohen P, Munoz A, Strauss JF 3rd \& Devoto L 2007 Features of natural and gonadotropin-releasing hormone antagonist-induced corpus luteum regression and effects of in vivo human chorionic gonadotropin. Journal of Clinical Endocrinology and Metabolism 92 4436-4443. (https://doi.org/10.1210/jc.2007-0125)

Engmann L, Losel R, Wehling M \& Peluso JJ 2006 Progesterone regulation of human granulosa/luteal cell viability by an RU486-independent mechanism. Journal of Clinical Endocrinology and Metabolism 91 4962-4968. (https://doi.org/10.1210/jc.2006-1128)

Fair T, Hyttel P, Greve T \& Boland M 1996 Nucleus structure and transcriptional activity in relation to oocyte diameter in cattle. Molecular Reproduction and Development 43 503-512. (https://doi.org/10.1002/ (SICl)1098-2795(199604)43:4<503::AID-MRD13>3.0.CO;2-\#)

Fair T, Hyttel P, Lonergan P \& Boland MP 2001 Immunolocalization of nucleolar proteins during bovine oocyte growth, meiotic maturation, and fertilization. Biology of Reproduction 64 1516-1525. (https://doi. org/10.1095/biolreprod64.5.1516)

Ginisty H, Sicard H, Roger B \& Bouvet P 1999 Structure and functions of nucleolin. Journal of Cell Science 112 761-772.

Griffin D, Liu X, Pru C, Pru JK \& Peluso JJ 2014 Expression of progesterone receptor membrane component-2 within the immature rat ovary and its role in regulating mitosis and apoptosis of spontaneously immortalized granulosa cells. Biology of Reproduction 91 36. (https://doi.org/10.1095/ biolreprod.114.117481)

Hand RA \& Craven RJ 2003 Hpr6.6 protein mediates cell death from oxidative damage in MCF-7 human breast cancer cells. Journal of Cellular Biochemistry 90 534-547. (https://doi.org/10.1002/jcb.10648)

Iftode C, Daniely Y \& Borowiec JA 1999 Replication protein A (RPA): the eukaryotic SSB. Critical Reviews in Biochemistry and Molecular Biology 34 141-180. (https://doi.org/10.1080/10409239991209255)

Jia W, Yao Z, Zhao J, Guan Q \& Gao L 2017 New perspectives of physiological and pathological functions of nucleolin ( $\mathrm{NCL}$ ). Life Sciences 186 1-10. (https://doi.org/10.1016/j.Ifs.2017.07.025)
Jiang B, Zhang B, Liang P, Song J, Deng H, Tu Z, Deng G \& Xiao X 2010 Nucleolin/C23 mediates the antiapoptotic effect of heat shock protein 70 during oxidative stress. FEBS Journal 277 642-652. (https://doi. org/10.1111/j.1742-4658.2009.07510.x)

Kabe Y, Nakane T, Koike I, Yamamoto T, Sugiura Y, Harada E, Sugase K, Shimamura T, Ohmura M, Muraoka K et al. 2016 Haem-dependent dimerization of PGRMC1/Sigma-2 receptor facilitates cancer proliferation and chemoresistance. Nature Communications 711030. (https://doi.org/10.1038/ncomms11030)

Keator CS, Mah K \& Slayden OD 2012 Alterations in progesterone receptor membrane component 2 (PGRMC2) in the endometrium of macaques afflicted with advanced endometriosis. Molecular Human Reproduction 18 308-319. (https://doi.org/10.1093/molehr/gas006)

Kowalik MK, Martyniak M, Rekawiecki R \& Kotwica J 2016 Expression and immunolocalization of membrane progesterone receptors in the bovine oviduct. Domestic Animal Endocrinology 55 83-96. (https://doi. org/10.1016/j.domaniend.2015.12.001)

Lee YJ, Wei HM, Chen LY \& Li C 2014 Localization of SERBP1 in stress granules and nucleoli. FEBS Journal 281 352-364. (https://doi. org/10.1111/febs.12606)

Lodde V \& Peluso JJ 2011 A novel role for progesterone and progesterone receptor membrane component 1 in regulating spindle microtubule stability during rat and human ovarian cell mitosis. Biology of Reproduction 84 715-722. (https://doi.org/10.1095/biolreprod.110.088385)

Lodde V, Modina S, Maddox-Hyttel P, Franciosi F, Lauria A \& Luciano AM 2008 Oocyte morphology and transcriptional silencing in relation to chromatin remodeling during the final phases of bovine oocyte growth. Molecular Reproduction and Development 75 915-924. (https://doi. org/10.1002/mrd.20824)

Luciano AM, Lodde V, Franciosi F, Ceciliani F \& Peluso JJ 2010 Progesterone receptor membrane component 1 expression and putative function in bovine oocyte maturation, fertilization, and early embryonic development. Reproduction 140 663-672. (https://doi.org/10.1530/REP10-0218)

Luciano AM, Corbani D, Lodde V, Tessaro I, Franciosi F, Peluso JJ \& Modina S 2011 Expression of progesterone receptor membrane component-1 in bovine reproductive system during estrous cycle. European Journal of Histochemistry 55 e27. (https://doi.org/10.4081/ejh.2011.e27)

Luciano AM, Franciosi F, Lodde V, Tessaro I, Corbani D, Modina SC \& Peluso JJ 2013 Oocytes isolated from dairy cows with reduced ovarian reserve have a high frequency of aneuploidy and alterations in the localization of progesterone receptor membrane component 1 and aurora kinase B. Biology of Reproduction 8858.

Maddox-Hyttel P, Bjerregaard B \& Laurincik J 2005 Meiosis and embryo technology: renaissance of the nucleolus. Reproduction, Fertility and Development 17 3-14. (https://doi.org/10.1071/RD04108)

Meyer C, Schmid R, Scriba PC \& Wehling M 1996 Purification and partial sequencing of high-affinity progesterone-binding site(s) from porcine liver membranes. European Journal of Biochemistry 239 726-731. (https://doi.org/10.1111/j.1432-1033.1996.0726u.x)

Miguel F, Augusto AC \& Gurgueira SA 2009 Effect of acute vs chronic H2O2induced oxidative stress on antioxidant enzyme activities. Free Radical Research 43 340-347. (https://doi.org/10.1080/10715760902751894)

Min L, Strushkevich NV, Harnastai IN, Iwamoto H, Gilep AA, Takemori H, Usanov SA, Nonaka Y, Hori H, Vinson GP et al. 2005 Molecular identification of adrenal inner zone antigen as a heme-binding protein. FEBS Journal 272 5832-5843. (https://doi.org/10.1111/j.17424658.2005.04977.x)

Mir SU, Ahmed IS, Arnold S \& Craven RJ 2012 Elevated progesterone receptor membrane component $1 /$ sigma-2 receptor levels in lung tumors and plasma from lung cancer patients. International Journal of Cancer 131 E1-E9. (https://doi.org/10.1002/ijc.26432)

Mir SU, Schwarze SR, Jin L, Zhang J, Friend W, Miriyala S, St Clair D \& Craven RJ 2013 Progesterone receptor membrane component 1/ Sigma-2 receptor associates with MAP1LC3B and promotes autophagy. Autophagy 9 1566-1578. (https://doi.org/10.4161/auto.25889)

Neubauer H, Clare SE, Wozny W, Schwall GP, Poznanovic S, Stegmann W, Vogel U, Sotlar K, Wallwiener D, Kurek R et al. 2008 Breast cancer proteomics reveals correlation between estrogen receptor status and differential phosphorylation of PGRMC1. Breast Cancer Research 10 R85. (https://doi.org/10.1186/bcr2155)

Neubauer H, Adam G, Seeger H, Mueck AO, Solomayer E, Wallwiener D, Cahill MA \& Fehm T 2009 Membrane-initiated effects of progesterone on 
proliferation and activation of VEGF in breast cancer cells. Climacteric 12 230-239. (https://doi.org/10.1080/13697130802635637)

Neubauer H, Ma Q, Zhou J, Yu Q, Ruan X, Seeger H, Fehm T \& Mueck AO 2013 Possible role of PGRMC1 in breast cancer development. Climacteric 16 509-513. (https://doi.org/10.3109/13697137.2013.800038)

Peluso JJ 2006 Multiplicity of progesterone's actions and receptors in the mammalian ovary. Biology of Reproduction 75 2-8. (https://doi. org/10.1095/biolreprod.105.049924)

Peluso JJ \& Pru JK 2014 Non-canonical progesterone signaling in granulosa cell function. Reproduction 147 R169-R178. (https://doi.org/10.1530/ REP-13-0582)

Peluso JJ, Pappalardo A, Losel R \& Wehling M 2006 Progesterone membrane receptor component 1 expression in the immature rat ovary and its role in mediating progesterone's antiapoptotic action. Endocrinology 147 3133-3140. (https://doi.org/10.1210/en.2006-0114)

Peluso JJ, Liu X, Saunders MM, Claffey KP \& Phoenix K 2008 Regulation of ovarian cancer cell viability and sensitivity to cisplatin by progesterone receptor membrane component-1. Journal of Clinical Endocrinology and Metabolism 93 1592-1599. (https://doi.org/10.1210/jc.2007-2771)

Peluso JJ, Gawkowska A, Liu X, Shioda T \& Pru JK 2009 Progesterone receptor membrane component-1 regulates the development and Cisplatin sensitivity of human ovarian tumors in athymic nude mice. Endocrinology 150 4846-4854. (https://doi.org/10.1210/en.2009-0730)

Peluso JJ, Liu X, Gawkowska A, Lodde V \& Wu CA 2010a Progesterone inhibits apoptosis in part by PGRMC1-regulated gene expression. Molecular and Cellular Endocrinology 320 153-161. (https://doi. org/10.1016/j.mce.2010.02.005)

Peluso JJ, Liu X, Gawkowska A, Lodde V \& Wu CA 2010b Progesterone inhibits apoptosis in part by PGRMC1-regulated gene expression. Molecular and Cellular Endocrinology 320 153-161. (https://doi. org/10.1016/j.mce.2010.02.005)

Peluso JJ, Lodde V \& Liu X 2012 Progesterone regulation of progesterone receptor membrane component 1 (PGRMC1) sumoylation and transcriptional activity in spontaneously immortalized granulosa cells. Endocrinology 153 3929-3939. (https://doi.org/10.1210/en.2011-2096)

Peluso JJ, Yuan A, Liu X \& Lodde V 2013 Plasminogen activator inhibitor 1 RNA-binding protein interacts with progesterone receptor membrane component 1 to regulate progesterone's ability to maintain the viability of spontaneously immortalized granulosa cells and rat granulosa cells. Biology of Reproduction $\mathbf{8 8}$ 20. (https://doi.org/10.1095/ biolreprod.112.103036)

Raza FS, Takemori H, Tojo H, Okamoto M \& Vinson GP 2001 Identification of the rat adrenal zona fasciculata/reticularis specific protein, inner zone antigen (IZAg), as the putative membrane progesterone receptor. European Journal of Biochemistry/FEBS 268 2141-2147. (https://doi. org/10.1046/j.1432-1327.2001.02096.x)

Roy L, Laboissiere S, Abdou E, Thibault G, Hamel N, Taheri M, Boismenu D, Lanoix J, Kearney RE \& Paiement J 2010 Proteomic analysis of the transitional endoplasmic reticulum in hepatocellular carcinoma: an organelle perspective on cancer. Biochimica et Biophysica Acta 1804 1869-1881. (https://doi.org/10.1016/j.bbapap.2010.05.008)

Runko E, Wideman C \& Kaprielian Z 1999 Cloning and expression of VEMA: a novel ventral midline antigen in the rat CNS. Molecular and Cellular Neuroscience 14 428-443. (https://doi.org/10.1006/mcne.1999.0794)

Ryu CS, Klein K \& Zanger UM 2017 Membrane associated progesterone receptors: promiscuous proteins with pleiotropic functions - focus on interactions with cytochromes P450. Frontiers in Pharmacology 8159. (https://doi.org/10.3389/fphar.2017.00159)

Saint-Dizier M, Sandra O, Ployart S, Chebrout M \& Constant F 2012 Expression of nuclear progesterone receptor and progesterone receptor membrane components 1 and 2 in the oviduct of cyclic and pregnant cows during the post-ovulation period. Reproductive Biology and Endocrinology 10 76. (https://doi.org/10.1186/1477-7827-10-76)

Sakamoto H, Ukena K, Takemori H, Okamoto M, Kawata M \& Tsutsui K 2004 Expression and localization of 25-Dx, a membrane- associated putative progesterone-binding protein, in the developing Purkinje cell. Neuroscience 126 325-334. (https://doi.org/10.1016/j. neuroscience.2004.04.003)

Shin BK, Wang H, Yim AM, Le Naour F, Brichory F, Jang JH, Zhao R, Puravs E, Tra J, Michael CW et al. 2003 Global profiling of the cell surface proteome of cancer cells uncovers an abundance of proteins with chaperone function. Journal of Biological Chemistry 278 7607-7616. (https://doi.org/10.1074/jbc.M210455200)

Spector DL \& Lamond Al 2011 Nuclear speckles. Cold Spring Harbor Perspectives in Biology $\mathbf{3}$ a000646.

Tahir MZ, Reynaud K, Grimard B, Thoumire S, Chastant-Maillard S \& Saint-Dizier M 2013 Expression of nuclear and membrane progesterone receptors in the canine oviduct during the periovulatory period. Reproduction, Fertility and Development 25 1065-1076. (https://doi. org/10.1071/RD12108)

Tajrishi MM, Tuteja R \& Tuteja N 2011 Nucleolin: the most abundant multifunctional phosphoprotein of nucleolus. Communicative and Integrative Biology 4 267-275. (https://doi.org/10.4161/cib.4.3.14884)

Terzaghi L, Tessaro I, Raucci F, Merico V, Mazzini G, Garagna S, Zuccotti M, Franciosi F \& Lodde V 2016 PGRMC1 participates in late events of bovine granulosa cells mitosis and oocyte meiosis. Cell Cycle 15 2019-2032. (https://doi.org/10.1080/15384101.2016.1192731)

Thomas P, Pang Y \& Dong J 2014 Enhancement of cell surface expression and receptor functions of membrane progestin receptor alpha (mPRalpha) by progesterone receptor membrane component 1 (PGRMC1): evidence for a role of PGRMC1 as an adaptor protein for steroid receptors. Endocrinology 155 1107-1119. (https://doi.org/10.1210/en.2013-1991)

Thul PJ, Akesson L, Wiking M, Mahdessian D, Geladaki A, Ait Blal H, Alm T, Asplund A, Bjork L, Breckels LM et al. 2017 A subcellular map of the human proteome. Science $\mathbf{3 5 6}$ eaal3321.

Vega M, Carrasco I, Castillo T, Troncoso JL, Videla LA \& Devoto L 1995 Functional luteolysis in response to hydrogen peroxide in human luteal cells. Journal of Endocrinology 147 177-182. (https://doi.org/10.1677/ joe.0.1470177)

Will EA, Liu X \& Peluso JJ 2017 AG 205, a progesterone receptor membrane component 1 antagonist, ablates progesterone's ability to block oxidative stress-induced apoptosis of human granulosa/luteal cells dagger. Biology of Reproduction 96 843-854. (https://doi.org/10.1093/biolre/iox013)

Wu W, Shi SQ, Huang HJ, Balducci J \& Garfield RE 2011 Changes in PGRMC1, a potential progesterone receptor, in human myometrium during pregnancy and labour at term and preterm. Molecular Human Reproduction 17 233-242. (https://doi.org/10.1093/molehr/gaq096)

Xu J, Zeng C, Chu W, Pan F, Rothfuss JM, Zhang F, Tu Z, Zhou D, Zeng D, Vangveravong $\mathbf{S}$ et al. 2011 Identification of the PGRMC1 protein complex as the putative sigma-2 receptor binding site. Nature Communications 2 380. (https://doi.org/10.1038/ncomms1386)

Zhang L, Kanda Y, Roberts DJ, Ecker JL, Losel R, Wehling M, Peluso JJ \& Pru JK 2008 Expression of progesterone receptor membrane component 1 and its partner serpine 1 mRNA binding protein in uterine and placental tissues of the mouse and human. Molecular and Cellular Endocrinology 287 81-89. (https://doi.org/10.1016/j.mce.2008.02.012)

Zhang B, Wang H, Jiang B, Liang P, Liu M, Deng G \& Xiao X 2010 Nucleolin/C23 is a negative regulator of hydrogen peroxide-induced apoptosis in HUVECs. Cell Stress and Chaperones 15 249-257. (https:// doi.org/10.1007/s12192-009-0138-5)

Received 29 August 2017

First decision 25 September 2017

Revised manuscript received 20 December 2017

Accepted 12 January 2018 